\title{
Effectiveness of Nursing Educational Intervention on Physical Function among Coronary Artery Disease Patients
}

\author{
Lamiaa Salama ${ }^{1}$, Manal Hamed Mahmoud ${ }^{2}$ and Marwa Mosaad $\mathrm{Ali}^{\mathbf{3}}$
}

(1)Nursing teacher At Menouf Technical School of Nursing, (2) Professor of Medical Surgical Nursing- Faculty of Nursing-Benha university and (3) Assistant Professor of Medical Surgical Nursing-Faculty of Nursing-Benha University

\begin{abstract}
Background: Coronary artery disease is a major cause of morbidity and mortality throughout the world. Health educational intervention can improve Physical function of CAD patients. Aim of this study was to evaluate effectiveness of educational intervention on physical function among coronary artery disease patients. Research Design: A quasi experimental research design was utilized. Setting: This study was conducted in coronary care units and outpatient cardiac clinic at Benha University Hospitals. Sample: A purposive sample of 86 patients with coronary artery disease was included in the study. Tools of data collection: Two tools were used to collect the data; 1) interviewing questionnaire included patients`knowledge and physical function assessment. 2) Practical Checklist. Results: The highest percentage were male more than 50 years, $73.3 \%$ having chronic disease mainly hypertension. There were statistically significant difference in patients' knowledge, physical function and patients' practice $(\mathrm{p}<.001)$. Conclusion: The study demonstrated statistical significant improvement of patients' knowledge, physical function and practices post program phase compared to preprogram phase. Recommendations: Physical function for patients with CAD should be evaluated during the plan for treatment of patient with CAD by trained nurse.
\end{abstract}

Keywords: Coronary Artery Disease, Educational Intervention, Physical Function

\section{Introduction}

Coronary Artery Disease (CAD) is the leading global cause of mortality. However, more people now live with $\mathrm{CAD}$ and may need support to manage symptoms and reduce risk of future problems such as heart attacks. CAD is the buildup of atherosclerotic plaque in the blood vessels that supply oxygen and nutrients to the heart. These plaques can clog the arteries or damage the arteries, which limits or stops blood flow to the heart muscle (Khera, 2017).

Several risk factors lead to CAD including modifiable and non-modifiable risk factors. Modifiable risk factors included abnormal lipid levels, smoking, hypertension, abdominal obesity, unhealthy diet, mental stress, and diabetes. Non modifiable risk factors included male gender, age, and family history (Gheisari et al, 2020).

Physical function is any bodily movement that lead to increased energy expenditure and can be achieved by a variety of leisure-time, work or transportation-related activities. Exercise refers to physical activities that are planned, structured, repetitive, and intended to improve or maintain fitness, function, and health. Physical activity is also important for preserving physical function and mobility, which can then delay the onset of major disability (Dipietro et al., 2019). 
Education has been shown to improve knowledge, self-care behaviors and clinical outcomes for patients. Patients should be educated about appropriate cholesterol management, blood pressure, smoking cessation, and lifestyle (Boyde et al, 2018).

Cardiac nurses play a critical role in the treatment of CAD patients. Improving the information that cardiac patients receive during their stay in hospital. Providing patients with the knowledge, skills and confidence to better manage their condition, aid their recovery and improve their quality of life (Dobber et al, 2019).

\section{Significance of the study}

According to World Health Organization statistics, an estimated 17.7 million people died from Cardiovascular Diseases (CVDs) representing $31 \%$ of all global deaths. Of these deaths, an estimated 7.4 million were due to $\mathrm{CAD}$ and 6.7 million were due to stroke. Over three quarters of CVD deaths take place in low- and middleincome countries (World Health Organization, 2016). Also Egypt death rate from coronary artery disease reached $24.58 \%$ of total deaths. The age adjusted Death Rate is 216.82 per 100,000 of population ranks Egypt (World Health Organization, 2017).

\section{Aim of the study}

The aim of the study was to evaluate effectiveness of nursing educational intervention on physical function among coronary artery disease patients.

\section{Research Hypothesis:}

Physical function among CAD patients will be significantly enhanced after execution of educational intervention.

\section{Subjects and method}

Research design:

A quasi experimental research design was utilized

\section{Setting:}

This study conducted at the coronary care unit (CCU) and Cardiology out-patient clinics at Benha University Hospital

\section{Sample:}

Type: A purposive sample of 86 patients with coronary artery disease (angina and MI) from the total patients 110 admitted to Benha University Hospital at the last year 2018. The sample included patients from both genders, who are conscious, able to communicate and willing to participate in the study. Patients with associated disorders were excluded from the study.

Size: The sample size of patients calculated based on census report of admission in the CCU from Benha University Hospital during, 2019.

\section{Tools:}

The data was collected through the following tools:

Tool I: Interview questionnaire: It was involved four parts as the following: A-Socio-demographic characteristics of the studied subjects: Concerned with assessment of Socio-demographic characteristics of the patients. It was contained eight questions included age, gender, marital status, educational level, work, housing status, financial income, and source of treatment.

B-Past and family history assessment: Concerned with assessment of Past and family history of the patients. It was 
contained seven questions about past medical history, smoking, exercise, family history of cardiac disease and degree of relationship.

C-Present medical history assessment: It was contained questions about chief complaints, present complication, and type of present complication.

\section{D-Patient's knowledge assessment:} Concerned with assessment Patient's knowledge regarding CAD for developing the booklet of educational program, it was designed by researcher in Arabic form to avoid misunderstanding and applied as pre and post tests for the study subjects. It is consisted of MCQ questions which covered the patient's knowledge about definition, manifestations, diagnosis, line of treatment, medical treatment, medication side effects, surgical management, complications, and nutrition.

\section{E- Physical function assessment questionnaire:}

This tool was developed by the researcher based on updated literature review. It contained questions to assess physical function including simple manual skills, activities of daily living, Physical exertion, movement and balance as well as Physical activities. It was a scale of five option; unable to perform, much difficulty, some difficulty, with a little difficulty, without any difficulty.

\section{Tool II: Practical Checklist:}

It consisted of two parts to evaluate patient's skills:

\section{Part 1: Coughing and breathing exercises:}

It contains seven items. Each item is scored "zero" for not done and one for done with the correct way; and these points are counted for each patient. The general patient practice is classified into poor practice if the score is <
$50 \%$, average good practice if the score is $50 \%-70 \%$ and Good if the score $>70 \%$.

\section{Part 2: Heart rate and rhythm evaluation:}

It contains eight items. Each item is scored "zero" for not done and one for done with the correct way; and these points are counted for each patient. The general patient practice is classified into poor practice if the score is < $50 \%$, average good practice if the score is $50 \%-70 \%$ and Good if the score $>70 \%$

\section{Tools validity}

The tools were reviewed by 3 experts in medical-surgical nursing and two cardiologists to ascertain their content validity. The tools were also reviewed for clarity, relevance, comprehensiveness, simplicity and applicability. Minor modifications were done.

\section{Ethical considerations}

At the initial interview, each potential subject was informed about the nature, purpose, benefit of the study, and informed that his/her participation is voluntary. Confidentiality of the subjects was also assured through coding of all data. The researcher assured that the data collected, and information will be confidential and would be used only to maintain patients` knowledge and practice that improve their health.

\section{Pilot study}

A pilot study for data collection was carried out in order to test whether the tools are clear, understandable, feasible, applicable and time consuming. Ten present from the total sample size that equal eight patients were selected randomly from cardiac units to participate in testing of the tools. Those patients were excluded from the study. 


\section{Field work}

The study was implemented from October 2020 to January 2021 where the researcher was available five days weekly.

\section{Assessment phase:}

The researcher started to recruit the sample according to eligibility criteria. Those who gave their consent were interviewed individually using the data collection form. The information obtained served as a baseline data or pretest, and guided the researchers in the preparation of the educational program.

\section{Planning Phase:}

Using the assessment data and related literature, the researcher developed an educational intervention to improve patients` knowledge and practice about coronary artery disease and related their physical function. The educational intervention included a theoretical and a practical part. The researcher prepared an educational intervention booklet in simple Arabic language to help patients assimilate and refresh the information provided to achieve the aim of the study.

\section{Implementation phase:}

The researcher met with the patients individually and administers the educational intervention. The intervention included the following part which covered coronary artery disease definition of $\mathrm{CAD}$, causes, risk factors, manifestation, diagnosis, and line of treatment, complication associated with the disease and the medication should be taken and the follow up. This will be followed by practical training in required practices include breathing and coughing exercises, heart rate and rhythms evaluation, assessment of discomfort degree associated with activity.

\section{Evaluation Phase:}

Each patient in this study was evaluated two times using the same data collection tools.

\section{Results}

Table (1): Shows that the studied patients had mean age 50.80 \pm 7.35 years, while $68.6 \%$ of them were in the range $51-60$ years old. In addition, $69.8 \%, 94.2 \%, 66.3 \%$ of the studied patients were male, married and had intermediate education respectively. Moreover, $46.5 \%$ \& $70.9 \%$ of the studied patients were employee and not having enough income.

Table (2): It reveals that $55.8 \%$ of the studied patients reported duration of illness from 1- 5 year. While $29.1 \%$ of the studied patients reported sudden onset of the disease and $90.7 \%$ of them discovered the disease by having signs and symptoms. In addition to 73.3 of them had chronic diseases; the most common chronic disease is hypertension among $50 \%$ and obesity among $23.3 \%$ of them. Also $17.4 \%$ of the studied patients had family history of Coronary artery disease. Moreover $52.3 \%$ of the studied patients had smoking history, and $75.6 \%$ of them were not practicing any exercise.

Table (3): It reveals that $90.7 \%$, $46.5 \%$ of the studied patients had chest pain followed by excessive sweating respectively. In addition, $39.5 \%, 32.6 \%$ and $27.9 \%$ of the studied patients reported weakness followed by difficulty of breathing and feeling dizzy respectively. Moreover $27.9 \%$ of the studied patients reported presence of complications, while $66.7 \%$ of them had arrhythmia.

Table (4): It reveals that there was a highly statistical significant difference in all 
items of simple manual skills between pre and post three months of program implementation ( $\mathrm{p}<$ 0.001). In addition, there were an improvement in patients simple manual skills post three months of program implementation than before, as wearing socks, pulling the covers up while sleeping on the bed and writing short sentences on the computer keyboard were improved from 2.60, 2.80 and 2.97 preprogram to $4.63,4.72$ and 4.71 post three months of program implementation respectively.
Table (5): It reveals that there was a highly statistical significant difference in all items of activities of daily living between pre and post three months of program implementation $(\mathrm{p}<$ 0.001). In addition, there were improvements in patients' activities of daily living post three months of program implementation than before, as putting on your clothes, Writing with a pen and washing your hair were improved from 2.51, 2.45 and 2.42 preprogram to $4.53,4.69$ and 4.69 post three months of program implementation respectively.

Table (1): Frequency distribution of studied patients according to their socio - demographic characteristics $(n=86)$

\begin{tabular}{|c|c|c|c|}
\hline \multicolumn{2}{|c|}{ Socio - demographic characteristics } & $\mathrm{N}=86$ & $\%$ \\
\hline \multirow[t]{5}{*}{ Age in year } & $<40$ & 8 & 9.3 \\
\hline & $40-50$ & 19 & 22.1 \\
\hline & $51-60$ & 59 & 68.6 \\
\hline & Min - Max & \multicolumn{2}{|c|}{$20-60$} \\
\hline & Mean \pm SD & \multicolumn{2}{|c|}{$50.80 \pm 7.35$} \\
\hline \multirow[t]{2}{*}{ Gender } & Male & 60 & 69.8 \\
\hline & Female & 26 & 30.2 \\
\hline \multirow[t]{2}{*}{ Marital status } & Married & 81 & 94.2 \\
\hline & Not married & 5 & 5.8 \\
\hline \multirow[t]{4}{*}{ Qualifications } & Not educated & 14 & 16.2 \\
\hline & Primary education & 10 & 11.6 \\
\hline & Intermediate education & 57 & 66.3 \\
\hline & University & 5 & 5.8 \\
\hline \multirow[t]{4}{*}{ Current job } & Employee & 40 & 46.5 \\
\hline & Manual work & 20 & 23.2 \\
\hline & House wife & 10 & 11.6 \\
\hline & No work & 16 & 18.6 \\
\hline \multirow[t]{3}{*}{ Efforts during the day $(n=70)$} & Physical effort & 36 & 51.4 \\
\hline & Mental effort & 24 & 34.3 \\
\hline & Written works & 10 & 14.2 \\
\hline
\end{tabular}


Effectiveness of Nursing Educational Intervention on Physical Function among Coronary Artery Disease Patients

Table (2): Frequency distribution of studied patients according to their past and family history $(n=86)$

\begin{tabular}{|c|c|c|c|}
\hline \multicolumn{2}{|c|}{ Past and Family history } & $\mathbf{N}=86$ & $\%$ \\
\hline \multirow[t]{3}{*}{ Duration of illness } & $<1$ year & 17 & 19.8 \\
\hline & From 1 - 5 year & 48 & 55.8 \\
\hline & $>5$ years & 21 & 24.4 \\
\hline \multirow[t]{2}{*}{ Onset of illness } & Sudden & 25 & 29.1 \\
\hline & Chronic & 61 & 70.9 \\
\hline \multirow[t]{3}{*}{ Discover of illness } & Having signs and symptoms & 78 & 90.7 \\
\hline & During medical examination & 3 & 3.5 \\
\hline & Accidents & 5 & 5.8 \\
\hline \multirow[t]{3}{*}{ Chronic diseases } & Hypertension & 43 & 50.0 \\
\hline & Obesity & 20 & 23.3 \\
\hline & No chronic disease & 23 & 26.7 \\
\hline \multicolumn{2}{|l|}{ Family history } & 15 & 17.4 \\
\hline \multicolumn{2}{|l|}{ Smoking history } & 45 & 52.3 \\
\hline \multirow[t]{2}{*}{ The type of smoking $(n=45)$. } & Cigarettes & 25 & 55.6 \\
\hline & Shisha & 20 & 44.4 \\
\hline \multirow[t]{3}{*}{ Type of exercise $n=21$} & Walking & 10 & 47.6 \\
\hline & Climbing stirs & 6 & 28.6 \\
\hline & Cycling & 5 & 23.8 \\
\hline
\end{tabular}

Table (3): Frequency distribution of studied patients according to their recent medical history $\mathbf{N}=\mathbf{8 6}$.

\begin{tabular}{|c|c|c|c|}
\hline & Medical history & $\mathrm{N}=86$ & $\%$ \\
\hline \multirow[t]{8}{*}{ Symptoms } & Chest pain & 78 & 90.7 \\
\hline & Palpitation & 15 & 17.4 \\
\hline & Difficulty of breathing & 28 & 32.6 \\
\hline & Nausea & 18 & 20.9 \\
\hline & Feeling dizzy & 24 & 27.9 \\
\hline & Excessive sweating & 40 & 46.5 \\
\hline & Weakness & 34 & 39.5 \\
\hline & Others & 2 & 2.3 \\
\hline \multicolumn{2}{|c|}{ Presence of complications } & 24 & 27.9 \\
\hline \multirow[t]{3}{*}{ If yes $(n=24)$} & Heart attack & 8 & 33.3 \\
\hline & arrhythmia & 16 & 66.7 \\
\hline & Heart failure & 0 & $0 \%$ \\
\hline
\end{tabular}


Table (4): Significant differences regarding physical function (simple manual skills) among the studied patients pre and post program implementation $\mathrm{N}=86$

\begin{tabular}{|c|c|c|c|c|c|c|}
\hline \multirow[t]{2}{*}{ Simple manual skills } & \multicolumn{2}{|l|}{ Pre } & \multicolumn{2}{|c|}{ Post 3months } & \multirow[t]{2}{*}{ t test } & \multirow[t]{2}{*}{ p-value } \\
\hline & Mean & \pm SD & Mean & \pm SD & & \\
\hline Raising hands above the head & 2.99 & .847 & 4.70 & .595 & 21.153 & $\mathrm{p}<0.001 * *$ \\
\hline Wearing socks & 2.60 & .924 & 4.63 & .614 & 21.301 & $\mathrm{p}<0.001 * *$ \\
\hline Tie shoelaces & 2.74 & .923 & 4.62 & .654 & 20.734 & $\mathrm{p}<0.001 * *$ \\
\hline Turning the pages of the book & 2.88 & .873 & 4.71 & .591 & 21.989 & $\mathrm{p}<0.001 * *$ \\
\hline $\begin{array}{l}\text { Pulling the covers up while } \\
\text { sleeping on the bed }\end{array}$ & 2.80 & .879 & 4.72 & .546 & 28.805 & $\mathrm{p}<0.001 * *$ \\
\hline Using the key to open the door & 2.85 & .901 & 4.65 & .647 & 25.117 & $\mathrm{p}<0.001^{* *}$ \\
\hline Turning on and off sink faucets & 2.76 & .957 & 4.60 & .656 & 24.096 & $\mathrm{p}<0.001 * *$ \\
\hline $\begin{array}{l}\text { Writing short sentences on the } \\
\text { computer keyboard }\end{array}$ & 2.97 & .804 & 4.71 & .550 & 33.040 & $\mathrm{p}<0.001 * *$ \\
\hline Total & 22.59 & \pm 6.61 & 37.33 & \pm 3.85 & 32.05 & $\mathrm{p}<0.001 * *$ \\
\hline
\end{tabular}

Table (5): Significant differences regarding physical function (Activities of daily living) among the studied patients pre and post program implementation $\mathrm{N}=86$

\begin{tabular}{|l|l|l|l|l|l|l|}
\hline \multirow{2}{*}{ Activities of daily living } & \multicolumn{2}{l}{ Pre } & \multicolumn{2}{l}{ Post 3months } & \multirow{2}{*}{ t test } & \multirow{2}{*}{ p-value } \\
\cline { 2 - 7 } & Mean & $\mathbf{4}$ SD & Mean & $\mathbf{\pm S D}$ & & \\
\hline Putting on clothes & 2.51 & .793 & 4.53 & .608 & 36.920 & $\mathrm{p}<0.001^{* *}$ \\
\hline Washing dishes and utensils & 2.45 & .746 & 4.63 & .614 & 37.649 & $\mathrm{p}<0.001^{* *}$ \\
\hline Cutting nails & 2.62 & .785 & 4.74 & .513 & 30.495 & $\mathrm{p}<0.001^{* *}$ \\
\hline $\begin{array}{l}\text { Removing the covers from small } \\
\text { things }\end{array}$ & 2.66 & .729 & 4.72 & .546 & 34.049 & $\mathrm{p}<0.001^{* *}$ \\
\hline Writing with a pen & 2.45 & .746 & 4.79 & .437 & 33.671 & $\mathrm{p}<0.001^{* *}$ \\
\hline Brushing teeth & 2.47 & .731 & 4.65 & .569 & 37.363 & $\mathrm{p}<0.001^{* *}$ \\
\hline Washing hair & 2.42 & .818 & 4.69 & .599 & 31.936 & $\mathrm{p}<0.001^{* *}$ \\
\hline Putting on clothes & 2.51 & .793 & 4.53 & .608 & 36.920 & $\mathrm{p}<0.001^{* *}$ \\
\hline Washing dishes and utensils & 2.45 & .746 & 4.63 & .614 & 37.649 & $\mathrm{p}<0.001^{* *}$ \\
\hline $\begin{array}{l}\text { Doing household chores such as } \\
\text { sweeping carpets or mopping } \\
\text { floors }\end{array}$ & 2.23 & .714 & 4.52 & .698 & 38.609 & $\mathrm{p}<0.001^{* *}$ \\
\hline Total & & & & & & \\
\hline
\end{tabular}




\section{Effectiveness of Nursing Educational Intervention on Physical Function among Coronary Artery}

\section{Disease Patients}

\section{Discussion}

Coronary artery disease is the most common type of heart disease. It is the leading cause of death in the United States in both men and women (Medline plus, 2021). Education is a common element of care for people with CAD aiming to decrease mortality and morbidity as well as improving quality of life (Brown, 2017).

\section{Regarding socio-demographic}

characteristics, results of the present study showed that the age of the studied patients ranged from 20 - 60 years old with the mean of 50 years. More than half of the studied patients ranged from 51 - 60 years old. The finding of the present study is supported with Athbi\& Hassan, (2019) in their study on Knowledge of patients with coronary heart disease about secondary prevention measure, whom showed that more than three fifth of the studied patients ranged in age from $50-60$ years old. Finding of the current study indicates aged patients have a high prevalence of CAD.

Related to sex, the present study revealed that more than three quarters of the studied patients were males. The present result is consistent with Salameh et al. (2012), in their study on Effect of an e-learning program on the quality of life of patients with coronary heart disease, whom showed that more than half of the studied patients were males. On the other hand Mahmoud\&Elderiny, (2018) in their study on Effect of lifestyle modification intervention on health status of coronary artery disease patients, who showed that more than half of the studied patients were females. The findings of the current study could be related to that smoking and occupational habits increase risk of CAD which mainly prevalent among males.

Related to marital status, the present study revealed that most of the studied patients were married. This result is consistent with Eaker et al, (2007) in their study on marital status, marital strain, and risk of coronary heart disease or total mortality, who found that more than half of the studied patients are married. In the same line Schwandt, et al, (2010) in their study on marital status, hypertension, coronary heart disease, diabetes, and death among African American women and men. This indicates that the family needs and loads could be the cause of coronary artery disease.

The result of the present study is consistent with Qadir, et al, (2019) in their study on Healthy Individuals and Coronary Artery Disease Patients Knowledge Regarding Diet and Exercise, who revealed that the majority of the studied patients had intermediate education. While the present finding disagreed with Tawalbeh, et al, (2015) in their study on the relationship between social support and adherence to healthy lifestyle among patients with coronary artery disease in the north of Jordan, whom showed that majority of the studied patients were more than secondary. The present finding could explain that $\mathrm{CAD}$ can occur to all peoples either educated or not.

The present study revealed that most of the studied patients living in the ground floor. This explains their ancient culture that CAD patients should not do exercise and climbing stairs. As well as more than two thirds of the studied patients do not have enough monthly 
income. This explains that low income lead to decrease adherence to medical examination and early detection. Also decrease income act as a source of stress on people which lead to chronic diseases.

With regards to medical history of the studied patients, the present study revealed that more than three quarters of the studied patients complained of the disease from less than five years. This finding could be related to decrease awareness about importance of periodic follow up and general examination.

The present study revealed that most of the studied patients had chronic diseases. This finding is supported by Park et al, (2019) reported the most common disease was hypertension that present in more than half of the studied patients followed Obesity. This indicates that high blood pressure alone or in association with obesity increases the risk of CAD.

As regards to physical function, The current study showed that there is an improvement in physical function (simple manual skills) after three months of program implementation, This result is consistent with, Tawalbeh, et al, (2014) in his study on; The effect of cardiac education on knowledge and adherence to healthy lifestyle, who showed an improvement in simple manual skills after one month of program implementation.

The current study showed that there is an improvement in physical function (Activities of daily living) after three months of program implementation. This result is consistent with in his study on: Effects of a comprehensive cardiac rehabilitation program on quality of life in patients with coronary artery disease. Whom revealed that an improvement in activities of daily living after two months of program implementation.

\section{Conclusion}

On the light of the current study results, it can be concluded that, Coronary artery disease occurs more among males, aged more than 50 years old and the most contributing factors were hypertension, obesity and smoking. There was significant improvement of patients' knowledge, practices and Physical function in post program phases compared to preprogram phase. There were highly statistically significant correlations between patients' knowledge, physical function and practice.

\section{Recommendations:}

- Physical function for patients with CAD should be evaluated during the plan for treatment of patient with CAD by trained nurse.

- A simple written guideline (colored posters and booklet) for patients with CAD should be available in cardiac units that provide care.

\section{References}

Athbi, H. A., \& Hassan, H. B. (2019). Knowledge of patients with coronary heart disease about secondary prevention measures. Indian Journal of Public Health, 10(02).

Available@https://medlineplus.gov/coronaryarte rydisease.htmlDuplicate the study to determine the effect of educational prgram on postoperative patient outcome.

Boyde, M., Peters, R., New, N., Hwang, R., Ha, T., \& Korczyk, D. (2018). Self-care educational intervention to reduce 
Effectiveness of Nursing Educational Intervention on Physical Function among Coronary Artery Disease Patients

hospitalisations in heart failure: a randomised controlled trial. European Journal of Cardiovascular Nursing, 17(2), 178-185.

Brown, J. P., Clark, A. M., Dalal, H., Welch, K., \& Taylor, R. S. (2017).Patient education in the management of coronary heart disease. Cochrane Database of Systematic Reviews, (12).

Dipietro, L., Campbell, W. W., Buchner, D. M., Erickson, K. I., Powell, K. E., Bloodgood, B., ... \& Olson, R. D. (2019). Physical activity, injurious falls, and physical function in aging: an umbrella review. Medicine \& Science in Sports \& Exercise, 51(6), 1303-1313.

Dobber, J., Latour, C., Snaterse, M., van Meijel, B., Ter Riet, G., Scholte op Reimer, W., \& Peters, R. (2019). Developing nurses' skills in motivational interviewing to promote a healthy lifestyle in patients with coronary artery disease. European Journal of Cardiovascular Nursing, 18(1), 28-37.

Gheisari, F., Emami, M., Raeisi Shahraki, H., Samipour, S., \& Nematollahi, P. (2020). The Role of Gender in the Importance of Risk Factors for Coronary Artery Disease. Cardiology Research and Practice, 2020.

Khera, A. V., \& Kathiresan, S. (2017). Genetics of coronary artery disease: discovery, biology and clinical translation. Nature Reviews Genetics, 18(6), 331.

Mahmoud, M. H., \& Elderiny, S. N. (2018). Effect of lifestyle modificationintervention on health status of coronary artery disease patients:
Randomized Control Trial. International Journal of Studies in Nursing, 3(3), 127.

Mayo Clinic. ( 2021). Coronary artery disease, Availagle@ https://www.mayoclinic.org/diseases -conditions/coronary-artery-disease/symptomscauses/syc-20350613. Accessed on :8_4_2020 at 10:15 p.m.

Medline plus, (2021). Coronary artery disease

Salameh, B., Gomaa, N., El-Senousy, T., \& Salameh, O (2012). Effect Of An E-learning Program On The Quality Of life Of Patients With Coronary Heart Disease. Procedia-Social and Behavioral Sciences, 55,284-293.

Sevinç, S., \& Akyol, A. D. (2010). Cardiac risk factors and quality of life in patients with coronary artery disease. Journal of Clinical Nursing, 19(9-10), 1315-1325.

Tantaewy, N. M., Shebl, A. M., Shereif, W. I., \& Weheda, S. M. (2013). Effect of cardiac rehabilitation program on lifestyle pattern of patients with myocardial infraction. Journal of Biology, Agriculture and Healthcare, 3(8).

Tawalbeh, L. I., Tubaishat, A., Batiha, A. M., Al-Azzam, M., \& AlBashtawy, M. (2015). The relationship between social support and adherence to healthy lifestyle among patients with coronary artery disease in the north of Jordan. Clinical Nursing Research, 24(2), 121138. 
فعالية التدخل التربوي التمريضي على الوظيفة البدنية لدى مرضى الثريان التاجي

$$
\text { لمياء سلامة - منال حامد محمود - مروة مسعد علي }
$$

يُعد مرض الثريان التاجي سبيًا رئيسيًا للوفيات في جميع أنحاء العالم. يمكن أن يؤدي التنخل التثقيفي الصحي

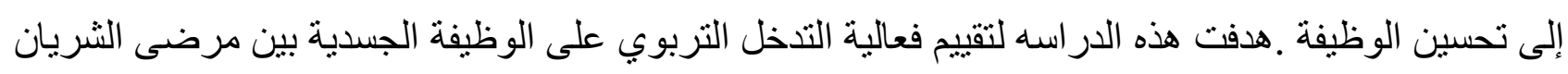

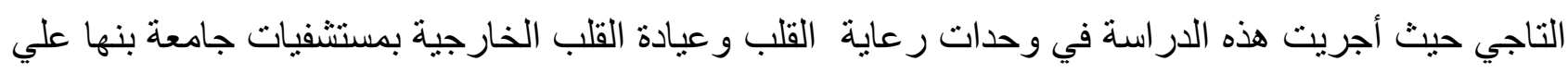

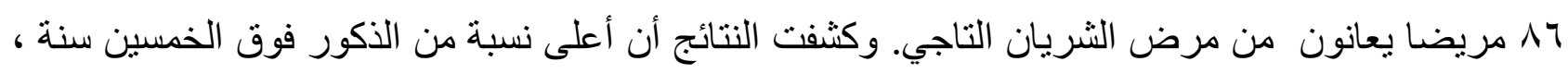

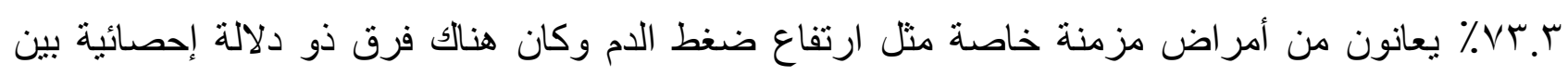

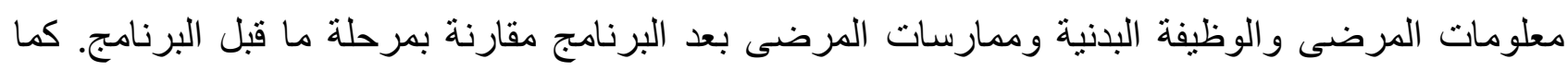

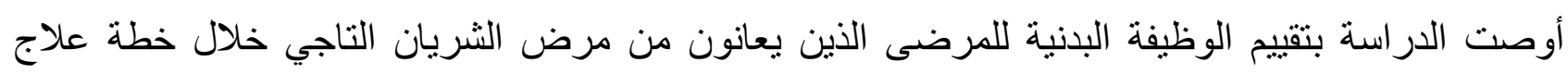
المريض من قبل ممرضة مدربة. 